\title{
Sharing teacher knowledge at scale: teacher inquiry, learning design and the representation of teachers' practice
}

Note: this is a pre-print version of the following article:

Oliver, M., Avramides, K., Clark, W., Hunter, J., Luckin, R., Hansen, C. \& Wasson, B. (2017)

Sharing teacher knowledge at scale: teacher inquiry, learning design and the representation of teachers' practice, Teacher Development.

Doi: $10.1080 / 13664530.2017 .1381642$

\section{Abstract}

Sharing teachers' professional knowledge remains challenging. Teachers' development often remains ad hoc or local, and attempts to scale this up have proved problematic.

To address this, research in areas such as 'learning design' has explored the use of formal representations of practice. This proposes that educational practice can be improved by documenting, sharing and building on what teachers already do.

Whilst this has led to some successes, it has not resulted in the widespread transformation of practice.

This paper reviews the literature about sharing teacher knowledge. The challenges of scaling up development are then considered in relation to two theories that help explain the challenges: Communities of Practice and Sociomateriality.

This analysis is illustrated through case studies in Norway and the UK. These show that teachers already create and share artefacts that represent their pedagogic knowledge. However, they found formal representations, such as learning designs, difficult to work with.

The paper concludes that scaling up teacher development using abstract formalisms is unlikely to succeed. Instead, teachers value stories and the materials they already create in their day-to-day practice. It is this intermediate level of 
representation, between direct experience and formal abstraction, that offers the most promise for sharing practice.

\section{Introduction}

Approaches to sharing teachers' expertise often fail when they move beyond local or 'pilot' initiatives, and attempt to effect change on a larger scale. This paper explores one response to this problem, investigating the ways in which teachers' knowledge is formalized and shared. Specifically, it explores how teachers represent their knowledge in their day-to-day practice, and the challenges associated with the introduction of new forms of representation, including formal representations in which knowledge is expressed, coded or structured in standardized ways.

First, the wider context of teacher development is reviewed, and teacher inquiry is explored as one approach to achieving this. This leads to the identification of sharing or 'scaling up' practice as a persistent challenge for teacher development. Consequently, the next section explores ways in which knowledge about practice is represented, including research into learning design. Potential limits to this approach are then identified in a third section, which uses two theoretical perspectives to develop a critique of representation. Then, two case studies are presented that illustrate the issues associated with sharing practice in this way. The paper concludes by identifying the ongoing challenges for teachers and researchers.

\section{The challenge of teacher development}

The idea of teachers learning from and through their day-to-day practice in schools is not new; as Zeichner (2012) argues, its history stretches back for the better part of a century. Teachers learn informally, by doing and by trial and error, and this happens whether or not they are also involved in formal professional development. However, it is argued that this day-to-day professional learning can be enhanced through the addition of formal elements, such as supervision (Grossman, 1990; Hoekstra \& Korthagen, 2011). Moreover, although practice-based learning grounds reforms in teachers' lived experience and expertise, relying on informal approaches such as exposure and imitation risks limiting the potential for teachers to learn through more deliberate experimentation, innovation and discovery (Wang et al, 2010). 
One crucial challenge in this area, however, is how the knowledge gained through such learning can be 'scaled up' (Lieberman \& Pointer Mace, 2010). Teaching has been characterized as taking place in isolation, which is why community-based approaches to teacher development are seen as increasingly important (Wardrip, Gomez \& Gomez, 2015). Approaches to teacher development can contribute to this isolation, rather than overcoming it. To illustrate this challenge, in the next section, work on teacher inquiry will be introduced.

\section{Teacher inquiry as an approach to development}

Teacher inquiry, also known as practitioner inquiry, is an approach to research and development that began in the 1980s, but whose origins can be traced back to Dewey's advocacy of teachers' reflective practice (Cochran-Smith and Lytle, 1999; Hines \& Conner-Zachocki, 2015). It develops the ideas of teacher knowledge advocated by Shulman (1986), understood in terms of the interaction between subject knowledge and pedagogical strategies, and focusing on the importance of attending to subject matter, the classroom context and the students' characteristics. Teacher inquiry is related to action research, critical inquiry and teacher research (Lytle and Cochran-Smith, 1994), in that the approach treats teacher knowledge as being complex and situated, and starts from the premise that teachers need to adapt what they do to varied learners and contexts (Wilson et al, 1987). It has also been described as a 'stance', an idea which can help to "capture the ways we stand, the ways we see, and the lenses we see through" (Cochran-Smith and Lytle, 1999: 288; cf. Zuidema, 2012). Cochran-Smith and Lytle (1999) point to its focus on personal experience, involving systematic, intentional, selfcritical inquiry about one's own work; Ritchie (2006) similarly associates it with teachers conducting their own research, in real classrooms and school settings, focusing on local issues which may or may not be generalisable to wider contexts. Whilst this specificity makes such approaches rich and meaningful, however, it also gives rise to the challenges of 'scaling up' change and development.

Dana \& Yendol-Hoppey (2008) locate the origins of teacher research in three educational research traditions (Table 1) identified as: process-product, qualitativeinterpretative and teacher inquiry. They argue that the first two represent an "outsider" perspective which has, in the past, tended to dominate school-based research. The latter "insider" perspective - which may offer valuable and potentially more meaningful 
insights to those learning how to teach - has been limited by traditions of knowledgebuilding defined by the academy. This split is defined in part by the claims made in each traditions to generally applicable knowledge.

\begin{tabular}{|c|c|c|c|}
\hline & Process-Product & $\begin{array}{l}\text { Qualitative or } \\
\text { Interpretative }\end{array}$ & Teacher Inquiry \\
\hline Teacher & Teacher as technician & $\begin{array}{l}\text { Teacher as story } \\
\text { character }\end{array}$ & Teacher as story teller \\
\hline Researcher & Outsider & Outsider & Insider \\
\hline Process & Linear & Discursive & Cyclical \\
\hline Question Source & Researcher & Researcher & Teacher \\
\hline Question Type & $\begin{array}{l}\text { Focused on control, } \\
\text { prediction, or impact }\end{array}$ & $\begin{array}{l}\text { Focused on explaining a } \\
\text { process or phenomenon }\end{array}$ & $\begin{array}{l}\text { Focused on providing insight into a } \\
\text { teacher's classroom practice in an effort } \\
\text { to make change }\end{array}$ \\
\hline $\begin{array}{l}\text { Question } \\
\text { Examples }\end{array}$ & $\begin{array}{l}\text { Which management } \\
\text { strategy is most } \\
\text { successful? }\end{array}$ & $\begin{array}{l}\text { How do children } \\
\text { experience bullying in } \\
\text { the classroom? }\end{array}$ & $\begin{array}{l}\text { How can I accommodate ESL students at } \\
\text { the kindergarten writing table? }\end{array}$ \\
\hline
\end{tabular}

Table 1: Insider-Outsider Research Paradigms (adapted from Dana \& Yendol-Hoppey, 2008: p7)

In line with its definition as systemic, intentional and contextual, teacher inquiry adopts a definite, planned, purposeful and action-oriented stance. Dana \& Yendol-Hoppey (2008) identify common features in the literature, in spite of the different traditions that inform individual approaches:

- Posing a question or 'wondering'

- Collecting data

- Analysing data and literature

- Making changes in practice

- Sharing findings with others

Dana and Yendol-Hoppey (2008) identify several benefits to this approach, including the generation of theories and knowledge grounded in the realities of educational practice. In this, it picks up well-established ideas about teacher knowledge needing to relate to students and contexts, as well as to disciplines and general pedagogic advice (Wilson et al, 1987; Grossman, 1990). However, there are also limitations to the approach, including concerns about the rigour and validity of the evidence base; the need for training, orientation or support in using research methods; potential risks from lack of motivation, time or capacity to undertake the work; and that the variation of school systems can result in low levels of generalisability (Rust, 2009, Dawson, 2007). 
Methodologically, Rust (2009) suggests that because teacher inquiry is embedded in the everyday practices and timeframes of teachers' lives in classrooms, teachers:

[...] have a readily available toolkit, including: classroom maps, anecdotal records, time-sampled observations, samples of student work, drawings and photographs, audio and video recordings, interviews, conversations, surveys, and teacher's journals, which can be used, over time, to answer questions about practice.

These artefacts are viewed as resources for undertaking the inquiry; however, their role in supporting sharing or generalisation has not been directly explored. It is this issue that will be turned to next.

\section{Sharing practice}

In order to move beyond individual instances of practice, it must be shared. However, the process of sharing is not widely discussed, and is often treated as if developments could be transmitted simply by having teachers talk about them. Talking about practice can of course be valuable and effective - as, for example, in Wardrip et al's study (2015) of literacy work circles. However, such conversations are possible primarily where groups can meet.

Some initiatives have extended this kind of exchange beyond immediate geographical constraints by moving from conversation to writing. This can be seen, for example, in the use of online communities such as the Community of Teachers program, where teachers negotiate the goals and meanings of their profession, and share personal narratives (Barab, MaKinster \& Scheckler, 2003: 238).

In other cases, more formal structures or outputs are described. Dawson (2007), for example, talks of teachers presenting the findings of their inquiries ("often in terms of themes, pattern, categories, assertion or metaphors": p7) both in writing and at an annual, regional showcase. Tucker (2010), by contrast, focuses on processes rather than outputs, describing how teachers formed an inquiry team to explore issues in student writing, using analysis of existing data sets and observations of each others' classes. In order to address the problem of 'scaling up' this sharing of expertise, teachers need to be connected, for example through networks or online professional learning communities (Lieberman \& Pointer Mace, 2010). However, even when this can be achieved, the move away from immediate contexts to more diffuse networks creates the 
problem that academic knowledge must then be related back to practice-based experience (Goodyear \& Steeples, 2006). There are clearly many ways to do this; for example, one well established approach is through discussion, questioning and storytelling, which may be evidenced either by direct experience or through the texts that teachers share online (e.g. Zuidema, 2012). Whichever approach is chosen, however, it remains important to preserve a nuanced and complex understanding of what 'practice' means in the context of teaching, keeping it grounded in teachers' ongoing work in a meaningful way, in order to avoid "decomposing" teaching in a reductive manner (Lampert, 2010).

Research exploring the adoption of technologies in education, in particular, led to the identification of a particular example of this issue: teachers found it hard to share innovative practice, particularly at scale (Goodyear \& Steeples, 1998). In attempting to work with distributed communities of teachers, Goodyear \& Steeples found that "aspects of practice [...] are difficult to render through written language. It can also be very hard to articulate practical knowledge that is held and used in tacit form" (p16).

Consequently, they explored alternative formats with which to represent and thus share practice. These were described in increasing order of abstraction from practice as:

- 'raw' video clips of teaching (captured in an unobtrusive, "fly on the wall" format);

- think-aloud clips (also described as "talking while doing" - best suited to tasks normally performed alone);

- action-with-commentary clips ('raw' clips, to which the practitioner has added an explanatory voice-over);

- "talking head" clips, which describe and explain practice rather than showing it directly;

- prepared scripts (enacted from a pre-prepared account of practice); and

- professionally acted (prepared scripts undertaken by people who are actors rather than teachers).

Other work has also explored ways in which such multimodal resources can support professional reflection (e.g. Loo, 2013), identifying further forms of representations not included on this list - for example, teachers' blogs about their teaching and video podcasts of their students' performance (Lieberman \& Pointer Mace, 2010). However, 
the important point for this discussion is that all of these formats had their limitations as ways of representing and sharing practice. For example, even 'raw' clips can prove to be a valuable resource, supporting development of the capacity for reflection, of 'noticing' skills and possibly even subject knowledge (Marsh \& Mitchell, 2014); however, whilst these are easy to generate, the selection and presentation of useful sections from hours of material was time-intensive (Lieberman \& Pointer Mace, 2010). Transcripts of teaching can be created - for example, through live captioning - but this is expensive, and teachers rarely had enough time to go back over the transcripts, let alone review their performance (Skipp \& Tanner, 2015).

Subsequent work has developed these ideas by focusing on the ways in which such representations are created and used, differentiating between the creation of multimedia objects, their annotation and subsequent searching and browsing to find them (Goodyear \& Steeples, 2006). These processes of working with multimedia 'texts' enables teacher knowledge to be made public, so that it can be critiqued, built upon and passed on (Lieberman \& Pointer Mace, 2010).

An important focus that arose from Goodyear \& Steeples' differentiation between creating, annotating and searching was the idea that this process could be formalized, so that design principles could be abstracted from instances of practice. The idea of design patterns - developed in architecture, and adopted in software engineering where code re-use is widespread - was taken up as one possible way of formalizing and sharing successful teaching practice. Goodyear (2005) describes how, in architecture, this idea was developed "to democratise architecture and town planning by offering a set of conceptual resources that ordinary people could use in (re)shaping their environment"(p93).

Patterns can stand as formalised repertoires of solutions to problems in practice; however, other authors have shown an interest in codifying these ideas further. Such developments link back to software engineering, seeking to specify patterns in ways that can be incorporated within software environments (McAndrew et al, 2006). Examples might include executable sequences developed for software environments such as LAMS (Learning Activity Management System) (Laurillard, 2012: 222), or similar learning design tools. 
There are clear connections between this approach and Shulman's identification of pedagogical strategies as a component of teacher knowledge (1987: 5), and similarly with work exploring how outputs from teacher inquiry can be shared in order to change others' practices, as Goodyear explains:

Design patterns have a number of qualities which, in combination, give them the potential to be a useful way of sharing experience [...] A pattern is a solution to a recurrent problem in a context. [...] Context is important in helping constrain and communicate the nature of both problem and solution. Describing the context for the problem and its solution avoids over-generalisation. In addition, patterns should also teach. They should be written in such a way that they help the reader understand enough about a problem and solution that they can adapt the problem description and solution to meet their own needs. [...] The use of patterns, then, can be seen as a way of bridging between theory, empirical evidence and experience (on the one hand) and the practical problems of design. (Goodyear, 2005: 93)

Laurillard (2008) argues that the ideal of teachers acting as reflective practitioners or action researchers is typically "very far from the reality of teaching practice", but that they can be helped to build collective knowledge and understanding by sharing innovatory ideas and evidence of successful practice as pedagogic forms:

The teacher has to define the topic, provide the tools, goals and working versions for comparison - but the principle is the same, the form captures the pedagogy, and it is the teacher's task to interpret the form and customize it to their specific context. In this sense, generic pedagogic forms are commonplace throughout education. (Laurillard, 2008: 145)

This proposal forms the basis for an argument that teaching could be reconceptualised as a 'design science', requiring learning designs to be articulated, adopted, adapted, tested and improved (Laurillard, 2012). Laurillard argues that "the pedagogical pattern format is a good way of circulating the currency of ideas, but the teaching design community will also need the means of exchange that sustains this infrastructure around the patterns. This will be a mix of tools for generating designs, and repositories to store, organize, and provide search and access mechanisms" (p221). 
However, Laurillard recognises that such scientific practice is far removed from current teaching practice, where "the best teaching ideas are most likely to be developed in very specific subject matter contexts. They have even been referred to as 'signature pedagogies' of a discipline (Shulman 2005)" (p220). Abstraction therefore remains an issue. Teachers who have been asked to produce formal representations of their practice have often struggled to do so; consequently, it has proved necessary to support this process, for example by running workshops that bring together practitioners, designers and researchers in a facilitated and structured pattern creation process (Mor \& Winters, 2008). The workshops Mor \& Winters ran covered three broad steps - identify, develop and refine - and took from 2-6 hours; comments from participants, reported in their study, suggested that these events really needed to be even longer. Participants also reported having struggled with ideas from software engineering, such as inheritance, that were used to explain the relationship between patterns. Subsequent work showed that writing and developing such patterns requires specialist expertise, and that teachers needed time and support to develop this (Winters \& Mor, 2009: 1080). One proposal intended to help address this situation involved generalizing on the basis salient features identified across multiple case studies. Winters \& Mor proposed that this would allow typologies to be created (although it was noted that determining salience was "non-trivial"). However, whilst this helped to generate abstract patterns, only grounding the abstractions in relevant cases helped teachers to 'read' such patterns successfully.

The phenomenon we observed was quite clear: abstract design patterns were not an approachable representation of knowledge for teachers, educational designers and even educational researchers. We were left in a frustrating situation of presenting our peers with aggregated knowledge, which we were strongly convinced was relevant to their work, and seeing it politely rejected. This situation, however, changed dramatically once the patterns were linked back to the case studies. Such linkage allowed our audience to apply the familiar tools of analogy, connecting the patterns to their own experience. (Winters \& Mor, 2009: 1085).

All this work pursues a shared aim: improving collective practice around the design of teaching, through the abstraction and sharing of successful pedagogy. The common purpose with teacher inquiry is clear, although in that context teachers share the 
evidence base on which their claims are grounded. However, to date, these areas have not been connected. The design-based approach appears to offer a wider repertoire of formats in which teachers' knowledge about their practice can be shared; the issue it brings with it is the ongoing challenge of abstraction, both when they try to describe and represent their practice, and also when they try to relate such representations to their practice.

It should be noted that pattern-based approaches are only one way of reifying educational practice in order to develop teacher knowledge; other approaches also exist, such as the representations created through learner analytics. The dashboard created by the Visible Classroom project, for example, created representations from analyses of the full transcripts of classroom sessions (Skipp \& Tanner, 2015), such as charts of the teacher's average number of words spoken per minute; the number of teacher questions versus number of student questions; percentage of teacher dialogue per session; and an overview of responses to the pupil survey. Skipp \& Tanner report that teachers found this useful, although mainly as the starting point for discussion with peers, or when they reflected on comparisons between their profile and the aggregates of other teachers in their phase of schooling. Again, the abstraction of teaching practice per se was of limited value; without some collective basis for comparison, individuals' scores meant little.

In order to investigate the problematic relationship between practices and abstraction further, the next section will review theoretical perspectives linking practice and representation.

\section{Theoretical framework}

Questions about the link between representations and teachers' knowledge have been asked for decades. The specific issue described above sets the claims from design science advocating the power of abstraction against a body of work challenging the idea that pedagogy consists of generic principles that can be applied to any discipline (Wilson et al, 1987). From the perspective of work on teacher knowledge, representations of practice are not able to act simply as 'carriers' that can be applied unproblematically in a range of subject contexts; for this reason, sharing and scaling up developments remains challenging. Theoretical analyses help to show why this is the case. A useful point of departure for this analysis - indeed, one already drawn upon by Goodyear \& Steeples 
(1998) in the discussion of representations above - is provided by Communities of Practice (Wenger, 1998).

Wenger's framework outlines the conditions under which groups of people acting together can influence each other's practices. It provides an analytic framework, against which groups can be assessed. Groups that are counted as Communities of Practice demonstrate mutual engagement (diverse but frequent interaction, which could include conflict); a joint enterprise (negotiation of goals, and shared norms) and a shared repertoire (a shared history of techniques, concepts, activities and so on that can always be reinterpreted). These are characterized in terms of a series of tensions, one of which is between practice and reification. On this account, practices are the meaningful, dayto-day actions that people undertake; these consists of a:

"complex process that combines doing, talking, thinking, feeling, and belonging. It involves our whole person including our bodies, minds, emotions, and social relations" (Wenger, 1998: 56)

Reifications are abstractions from these practices, whose purpose is "giving form to our experience by producing objects that congeal this experience into thingness" (Wenger, 1998: 58).

Practice-based approaches to developing a shared teaching repertoire would involve teachers being co-present; this could be achieved through joint teaching, or peer observation of teaching. This requires coherent communities, and so would not support sharing widely across a sector or internationally.

Reifications, however, can act as 'boundary crossing objects'. Boundaries can act as important sites for learning (Akkerman \& Bakker, 2011), and Wenger argues that learning around boundaries is important to prevent communities of practice becoming introverted and stultifying. This approach to development clearly resonates with research into sharable representations of practice.

Such reifications are understood to be necessarily incomplete - for example, reifying information about industrial processes in control machinery changes the context of work, emphasizing specific features but depriving operators of other embodied expertise, such as the sounds associated with successfully running processes (Ramsten \& Saljo, 2012). As such, their meaning is rendered ambiguous. Learning, Wenger argues, 
arises from this ambiguity, particularly for objects that come from 'outside' of a group's established patterns of practice. Wenger proposes that "they are in fact the nexus of perspectives, and that it is often in the meeting of these perspectives that artifacts obtain their meanings" (Wenger, 1998: 108). In line with the claims of design science, such reifications can be shared across many communities, meaning that parallel but similar processes of meaning making can take place. This supports the idea that abstractions can be used to develop and align practice across multiple, non-overlapping communities.

Whilst this highlights the importance of reifications in supporting wide-ranging changes in practice, Wenger's discussion of reifications remains very general. Examples are provided, but these are illustrative, and do not provide the conceptual tools to analyze the production or subsequent use of other reifications. Studies that have explored such ideas empirically have shown that the creation and use of reifications is complex, subtle, and requires a close attention to the details of day-to-day practice. Introducing such reifications constitutes a change in the economy of meaning for a community, and some brokering of new practices may be necessary if they are to be successfully adopted (Ramsten \& Saljo, 2012).

The complexity of this process has led to practice, rather than reification, remaining the focus within work that draws on Communities of Practice in the context of teacher development. For example, Barab, MaKinster \& Scheckler (2003) have much more to say about forms of participation than they do about reification, simply noting that the design of the system their Community of Teachers uses itself reifies design practice (244). Further, they gloss over the relationship between video-based teaching vignettes and teaching practice, simply stating that participants' "beliefs, values, and understandings are reified within their videos, reflections, and discussion forum settings" (245).

What this shows is that further analysis is needed, in order to move beyond the general account and draw productive distinctions between different kinds of reification (Barton \& Hamilton, 2005). Barton \& Hamilton identify several candidate theories that would help achieve this, one of which is Actor-Network Theory (ANT). Here, their proposal will be taken up in terms of one of ANT's successor theories, sociomateriality.

Sociomaterial theory draws attention to the ways in which practices involve material artefacts as well as people, and how this involvement changes meaning. 
Humans, and what they take to be their learning and social process, do not float, distinct, in container-like contexts of education, such as classrooms or community sites, that can be conceptualised and dismissed as simply a wash of material stuff and spaces. The things that assemble these contexts, and incidentally the actions and bodies including human ones that are part of these assemblages, are continuously acting upon each other to bring forth and distribute, as well as to obscure and deny, knowledge. (Fenwick et al 2011)

Sociomateriality draws from Actor-Network Theory, sharing with it a focus on how social arrangements are achieved (Latour, 2005). Within the context of this discussion, it provides a fine-grained lens for studying the ways in which specific reifications are taken up by practitioners to either sustain or alter what they do. In this, it extends existing discussions about teacher knowledge - for example, the idea that teachers need knowledge of context is well established (Grossman, 1990), but this 'context' has been described primarily in terms of social and political relations, giving an immaterial account of culture. Sociomateriality draws attention back to the roles of material cultures, including those of texts, and how these can influence practices.

Central to ANT is the idea of 'actants': this proposes that the binary between people and objects is problematic, so that things should be classed agents if they are able to act in specific situations. This is directly relevant to the ideal of executable learning designs, for example, which would be classed as teaching agents, because the software would be able to enact a design without relying on a teacher to interpret and perform it. However, it can also be used to explain the way in which a representation of a specific learning design or a video clip of classroom practice might be understood to encourage a teacher to try teaching in a new way.

ANT also introduces the concept of 'immutable mobiles': things that remain recognizable even as they are taken up in new ways in different social settings. This concept explains how the creation, maintenance and deployment of material formalizations is integral to understanding the way that stable patterns of social relationship work - in other words, how practices become standardized (Latour, 2005: 237-8). This idea has been taken up in the context of educational policy, for example (Hamilton, 2011), revealing how processes of reification play into changes in power: 
In the final moment of mobilization the few come to speak as the many. There is one united voice and a new settlement which is no longer questioned. This is the stage at which 'black boxing' of previously unstable truths and meanings occurs. Policy has succeeded in imposing a new order on a social field-for the time being. (Hamilton, 2011: 61)

These ideas echo the trend towards abstraction in the design-based research into teachers' practice. It helps to explain the desire to move away from the immediate, material stuff of everyday teaching, towards abstract formalisations that can be used to standardize work on an international basis, using the kinds of pedagogic forms 'captured' in the pattern language or design science approach and then circulated for use amongst internationally-distributed communities (Laurillard, 2012).

Together, these accounts suggest the framework shown in Table 2 (with the differentiation of examples from informal to formal intended to be indicative and continuous, rather than categorical).

\begin{tabular}{|l|l|}
\hline \multicolumn{1}{|c|}{ Participation } & \multicolumn{1}{c|}{ Indirect, via reification } \\
\hline pirectly experienced - co-teaching, & $\begin{array}{l}\text { Unstructured - materials produced as } \\
\text { part of day-to-day practice, 'raw' video } \\
\text { clips of teaching, unedited transcripts } \\
\text { of teaching }\end{array}$ \\
\hline $\begin{array}{l}\text { Negotiated - conversations about } \\
\text { experience (i.e. participation in } \\
\text { discourse about teaching) }\end{array}$ & $\begin{array}{l}\text { Structured - case study accounts, } \\
\text { action-with-commentary video clips, } \\
\text { lesson plans, design patterns, } \\
\text { 'dashboard' representations of } \\
\text { indicators such as percent of teacher } \\
\text { dialogue, etc }\end{array}$ \\
\hline & $\begin{array}{l}\text { Codified - executable learning designs } \\
\text { (software as agent, able to 'act' without } \\
\text { interpretation by teachers) }\end{array}$ \\
\hline
\end{tabular}

Table 2: A framework for sharing teacher inquiry

This framework provides distinctions between forms of reification, of the kind that Barton and Hamilton (2005) called for, which may be productive in explaining the relative success or failure of different kinds of representation in changing practices. It 
uses the theoretical concepts introduced above to differentiate between ways of sharing teacher knowledge. At this stage, such differentiation is necessarily provisional: there are contradictions between Communities of Practice and sociomateriality. For example, from an Actor-Network perspective, a text or piece of software might be treated as having agency, and so a teacher working with it might be understood as engaging in joint practice, rather than experiencing another teacher's knowledge indirectly. Similarly, the process of classifying materials on the continuum from unstructured to codified might be influenced by a reader's ability to discern structures, irrespective of the author's intentions; this suggests a phenomenogical rather than an essential categorization. Moreover, further differentiation could be made in terms of:

- representations of pedagogic practice (such as pedagogic patterns) and representations of the processes of inquiry (such as how an evidence base warrants claims for the value of a design or pattern);

- the kinds of reification teachers can create themselves, and those that they can use to inform their practice in a way they find meaningful (so that a teacher might be able, for example, to relate an action-with-commentary video clip to their practice without being able to make one); and

- the kinds of reification they can produce or consume on their own, and those they are able to work with when the process is facilitated (for example, through the kinds of authoring workshop described in Winters \& Mor, 2009).

Nevertheless, this provisional framework can already be used to make sense of teachers' experiences as they try to share experiences in order scale up new practices.

In the next section of the paper, empirical work will be presented that was undertaken with teachers who undertook inquiries into their own practice. This will be used to explore which kinds of reifications teachers felt able to use to share their practice and inquiry.

\section{Illustrating the issues of sharing practice}

\section{Methodology}

To explore the different forms of representation teachers were able to share, two case studies were undertaken with teachers who had been involved in inquiry projects. These were used to identify the representations of practice and inquiry that teachers 
shared spontaneously, and those shared with the support of the project team; this helped to map out both existing practice, and also the possibilities that might be available when working in a supported or facilitated way.

The studies described here took place as part of the NEXT-TELL project, which explored how teachers can keep track of students' learning across time, location, media, and networks. The project supported teacher inquiry as a way of studying this in the context of contemporary school settings. The specific approach developed within the project was called TISL - Teacher Inquiry into Student Learning - which was defined as follows:

TISL is a systematic, intentional, design-oriented approach to teachers' technologysupported inquiry into students' learning. It focuses on the development and use of formative e-assessment methods using advanced learning technologies (digital tools) to capture, analyse, interpret, share and evaluate student data. In so doing, it aims to contribute to the development of teacher professionalism and school improvement through a focus on teacher-centred, practice-based, evidenceoriented research activity. The outcome of this activity is intended to bridge the communication gap between teachers, learners, parents, policymakers, school leaders and administrators and the wider community. (Clark, Luckin \& Jewitt, 2011)

TISL thus built on the existing literature on teacher inquiry, and technology-enhanced learning more generally, through an in-depth focus on the principled design of appropriate tools and methods that teachers can use to support their learning about students' learning; and to an enhanced awareness and understanding of teaching and learning in technology-rich learning contexts (Luckin, 2010).

The studies reported here involved teachers who undertook Teacher Inquiry projects as part of NEXT-TELL. Schools were selected from the UK and Norway to incorporate technology in their teaching practice. Within each school, teachers worked together, although the structures through which they did this differed.

The study in the UK involved teachers working at a private, international school. It is structured to provide low, middle and high school provision, and the curriculum includes U.S. High School Diplomas and International Baccalaureate Diplomas. The school was committed to using new technology, and instigated a 1:1 iPad programme for Grades 3-12. 50 teachers took part in the initial projects. 
In Norway, the study was carried out at an upper secondary school in Bergen. This public school, comprising three grades (VG1, VG2, VG3) and covering students from ages 16-19, was a digital school (Krumsvik, 2011). 10 teachers took part in the initial project work.

In each case, after the projects were completed, the participating teachers were invited to take part in a study to explore the ways in which they shared their practices in order to effect change. Seven took part from each school. In both schools, participants included both male and female teachers, and both experienced and new teachers. The teachers from both schools taught either science subjects or modern European languages In Norway, the teachers were interviewed together, as a focus group; in the UK, for logistical reasons, the teachers were interviewed separately. In both cases, participants were asked to bring along examples of materials that had influenced their Inquiry process, or which they had created to share with others.

The research received institutional ethical approval; participating teachers and schools have been anonymised or given pseudonyms, and all participants were informed of their right to withdraw at any time.

\section{Case 1: Teacher Inquiry into supporting student dialogue}

This inquiry project was led by two secondary school teachers at an international school in the UK, whose subjects were English and Technology. The focus of the inquiry was on supporting student dialogue in class. The teachers were supported by a recently established research centre within the school, which provided the time and resources to enable them to formulate, carry out and share the outcomes of their inquiries.

There were three phases to the inquiry. During the first phase, the lead teachers researched the literature on student dialogue, and strategies to support student dialogue in class. They then received support in determining the focus and scope of the inquiry from two staff at the school's research centre.

During the second phase, they invited colleagues (seven teachers, of whom two were in leadership roles) to participate in an evaluation of strategies to support student dialogue. One of the key concerns in inviting people was that participating in the inquiry would involve extra work, and, therefore, they chose colleagues they knew well something that has implications for sharing and scaling up practice. 
The lead teachers designed a practical day-long workshop. Teachers were asked to bring their lesson plans to the workshop, and a further 41 teachers took part in these. During the first half of the workshop, they discussed the research evidence on the effectiveness of student dialogue, linking this closely with the design of student activities. The second half of the workshop was dedicated to integrating student dialogue activities into teachers' existing lesson plans. Following the workshop, teachers videotaped their lessons and reflected on the impact of the new strategies on student learning. One of the lead teachers had expertise in media and, therefore, had the skills to set up microphones and cameras to capture quality video footage of student interactions. The video and teacher reflections were analysed by the two lead teachers.

The third phase of the inquiry focused on sharing the findings. The teachers' initial approach was to publish an eBook detailing strategies for supporting student dialogue, including five example lesson plans and short clips from the implementation of those lesson plans in class. However, they found that the book on its own was not used by teachers. After a period of two months, they developed a new approach to sharing the findings of the inquiry, based on the successful design of the workshop in phase two. The book is used as a resource during workshops; the focus of the workshops themselves is on integrating the strategies for supporting student dialogue into teachers' existing lesson plans. Teachers, therefore, now leave the revised workshop having already thought through how they will apply the new ideas to their teaching practice. The lead teacher's intention is to follow up the workshop by asking teachers whether they continue to use the strategies to support student dialogue, how these have been further adapted, as well as the impact on student learning. One of the challenges they reported at the time of the interviews was keeping track of teachers' use of student dialogue strategies - even those who participated in the original research in phase two, who had been selected on the basis of being well known to the two lead teachers.

\section{Case 2: Teacher inquiry into students' use of an Open Learner Model}

The second inquiry project was led by two secondary school teachers, both teaching Science, at an upper secondary school in Norway. The focus of their inquiry was the use of the Next-Tell Open Learner Model (OLM) (Bull \& Kay, 2013) as a tool for representing the students' own learning needs and current state of knowledge. After attending an initial workshop held on a Professional Development day, the teachers had to fit their 
inquiry work with the OLM between their teaching commitments, and on their own time in the evenings and on holidays. They often worked individually and had to find ways to share their work with each other. The plan was that they would eventually share their results more generally with other teachers in the school.

There have been two phases to the inquiry. During the first phase, the lead teachers participated in a professional development workshop where the researchers facilitated seven teachers in the first stages of the TISL Heart method (Hansen \& Wasson, 2016), the outcome of which was an inquiry question and a plan for the inquiry. Of the seven teachers, 3 were STEM teachers, and 4 teachers were language teachers (for French, Spanish, and two teachers of Norwegian to hearing impaired). They divided themselves into four groups. For the workshop, different coloured posters representing each step in the TISL Heart inquiry method were placed around the room. Each group was given their own colour of post-it notes, on which they wrote down relevant information for each step of the inquiry and placed them on the appropriate poster. They focused on all aspects of the inquiry model, including assumptions, the question, plan, change of teaching and assessment, learning outcomes, feedback, and sharing. After the groups were finished, their entries for each step were read aloud in a plenum, allowing for collective feedback from the other groups and the researchers.

One group continued to a second phase of work. During the first phase they expressed their inquiry question in terms of looking at "student's learning needs, current state of knowledge, and what needs students have in order to reach the goals. In addition investigate strategies that worked for each single student, for more variation". When refining this to produce a concrete inquiry question, they settled on, "How can we better take advantage of parallel teaching and teacher competence?"

The plan developed at this point was to use the OLM to visualize student competence from past performance in a range of different assessment situations. As they were not parallel teaching, the intention was to carry out the inquiry collectively, collaborating while configuring the OLM for each of their classes, discussing assessment situations to be used to collect data for the OLM, and planning to share the results and data from their own class with the others, to see if the use of the OLM led to different learning outcomes than a control group. Another part of their plan was to use formative assessment and summative assessment with feed-forward communication in their classes. They planned 
to collect data through the use of assessment criteria (oral, written, practical) from both classes and from control groups experiencing ordinary teaching, and then to analyse this.

Since the inquiry was planned as a collective approach, the teachers planned the following in ordered steps to share their inquiry:

1. Present the proposed change and (if any) improvement

2. Discuss change and (if) improvement

3. Reflect upon change and (if) improvement

In the focus group, they reported that when they tried to implement these plans, they had trouble following the inquiry method. They had been able to reflect on their use of the OLM, but had not been able to document the different steps specified within TISL. Although they had expected to use the TISL Heart tool to scaffold their collective inquiry process, due to technical difficulties, this proved impossible. As the tool failed, they were not able to carry out the intended inquiry process as planned; they reported that instead, they had to spend time figuring out how to collaborate without the tool and how to share their findings.

As mentioned earlier, the teachers were not parallel teaching so they were not allocated any time for working together. In the focus group, the teachers reported how they used lunch breaks and email to collaborate, and the school's LMS system, "Its' Learning", proved to be an important tool for their collaboration, in addition to Google docs and their mobile phones.

\section{Discussion}

These cases are provided primarily to illustrate the arguments developed through the theoretical critique. However, analyzing these accounts using the framework for sharing teacher inquiry reveals several features that are worthy of note. As shown in Table 3, the UK case relied on discussion, and on the processes of negotiation within existing communities that allow existing reifications of practice to be re-interpreted, and made meaningful in relation to local practice: 
The politics of reification requires participation because reification does not itself ensure any effect. Reifiation has to be adopted by a community before it can shape practice in significant ways (Wenger, 1998: 92).

This is in line with the studies of teacher inquiry or the Community of Teachers program (Barab, MaKinster \& Scheckler, 2003), but clearly not the kind of outcome hoped for by proponents of more formal design approaches (e.g. Laurillard, 2012).

\begin{tabular}{|l|l|}
\hline Participation & Indirect, via reification \\
\hline Directly experienced - none & $\begin{array}{l}\text { Unstructured/close to practice - video } \\
\text { of revised lessons }\end{array}$ \\
\hline $\begin{array}{l}\text { Negotiated - discussions about scope } \\
\text { and focus with staff from school's } \\
\text { research centre, discussing published } \\
\text { research in a workshop, negotiation of } \\
\text { revised lesson plans with peers, } \\
\text { workshops involving the eBook }\end{array}$ & teachers, local eBook (not used) \\
\hline & \\
\hline
\end{tabular}

Table 3: sharing inquiry in the UK case

The eBook is an interesting case in point: even though this was derived from local practice, taking place in the same school, peers still could not use it successfully without the discursive processes of meaning making within a workshop setting. This illustrates the challenges facing abstractions that are intended to help with the problem of scaling up by 'standing for' practice, such as pedagogic patterns. It is also consistent with the facilitated, workshop-based approaches adopted by Winters \& Mor (2009), and suggests that even codification in the form of a book of pedagogic suggestions can feel like a reductive decomposition of teaching (Lampert, 2010). This supports the conclusions of Goodyear \& Steeples (2006): that relating formalized knowledge to practical experience remains difficult.

Another related challenge arises from the extra work that these developments represented. These concerns about the time commitment are why the lead teachers invited others to participate whom they knew well. This suggests that forms of 
development relying on mutual participation are likely to replicate existing relationships, which may result in limited or conservative sharing, rather than wider or more systematic scaling up. Some degree of formal intervention might be necessary to move beyond this.

The other point to note in this case is how all the attempts to share practice were mediated by texts (understood in the multimodal sense, to include video). Published research forms an obvious example, but the case study is shot through with references to lesson plans and other such day-to-day materials, of the kind listed by Rust (2009); there is also reference to the kinds of 'raw' video clips valued by Marsh \& Mitchell (2014), although not to the other, more abstracted kinds of video listed by Goodyear \& Steeples (1998).

The consistent presence of such texts as a necessary component of reflection links to the sociomaterial argument that non-human 'actants' form important and necessary parts of successful practice. This suggests that the focus on communities and networks seen in, for example, Barab, MaKinster \& Scheckler (2003) needs complementing by further consideration of the material forms through which teachers' knowledge is expressed. Importantly, the kinds of formalism advocated in work on learning design remain conspicuously absent. Barab, MaKinster \& Scheckler (2003) do identify the value of teacher's written accounts; however, a far fuller treatment can be seen in Lieberman \& Pointer Mace (2010). Whilst their discussion of making knowledge public and subsequent critique does not focus on the material forms of such texts in close detail, it does recognize the pivotal role that the creation, reading and negotiation of such texts plays in the successful sharing of practice.

The study with Norweigan teachers reveals a different pattern, albeit one that continues to emphasize the role of negotiation, and which is also marked by the importance of close-to-practice forms of representation (Table 4).

\begin{tabular}{|l|l|}
\hline Participation & Indirect, via reification \\
\hline Directly experienced - joint teaching & Unstructured - emailed discussions of \\
using the OLM to visualize student & practice, data sets of student \\
competence & performance \\
\hline Negotiated - Posters and post-it notes & Structured - visualisations of student \\
\hline
\end{tabular}




\begin{tabular}{|l|l|}
\hline $\begin{array}{l}\text { in the workshop, discussion of } \\
\text { assessment options in the workshop, } \\
\text { discussions about practice in lunch } \\
\text { hours }\end{array}$ & performance through the OLM \\
\hline & Codified - use of the TISL tool (failed) \\
\hline
\end{tabular}

Table 4: sharing inquiry in the Norweigan case

In this case, the codification of practice in a machine-readable form failed for technical reasons; the teachers then abandoned this option in favor of less structured alternatives, rather than seeing sufficient value in the approach to try and fix the problem or find an equivalent alternative. This is evidence of the challenges of formalization previously seen by Winters \& Mor (2009), and also of the value to teachers of less formal discussions of practice, of the kinds being used by the Community of Teachers (Barab, MaKinster \& Scheckler, 2003). This suggests that the appeal of seeing teachers as story tellers or story characters (Dana \& Yendol-Hoppey, 2008) will be hard to overcome. The OLM digitized records of student achievement and offered the teachers visualizations of these This suggests a more codified form of practice - and yet this was taken up through joint teaching, with the representations being interpreted by a peer, whose presence meant that forms of practice could be shared through direct experience. From a sociomaterial perspective, whilst the OLM and its representations were incorporated as a new actant in the network, it replaced grade books and student profiles rather than reifying teachers' knowledge about context or pedagogy. The influence of the OLM was managed through negotiation with peers rather than radically disrupting existing, successful forms of practice. It replaced elements within teachers' existing ecology of resources (Luckin, 2010), rather than destabilizing the entire ecology.

Obviously, caution should be taken to avoid over-generalization from individual cases. The purpose of these cases is not to establish norms, but to demonstrate the theoretical points argued above. In both these cases, it is important to recognize that teachers already share their practice, and do so successfully. However, they rely on texts that reify their practice in order to do this. The most prevalent and easy to work texts in both cases were relatively unstructured (in the sense of being abstracted from existing practices), such as stories. A notable exception was with lesson plans: this formalization 
is something that the teachers worked with on a day-to-day basis within their existing practice, and which they were therefore familiar with creating, reading and reinterpreting. Unfamiliar reifications required support and facilitation.

To the extent that these patterns are repeated with other groups of teachers, this suggests that attempts to scale up the sharing of practice - for example, through sharing the process and outcomes of teachers' inquiries - may be best served by finding ways to work with the day-to-day texts that are already part of teachers' practice, rather than by developing new formalisms and expecting teachers to learn how to write, read and interpret these independently.

\section{Conclusions}

Teachers are surrounded by rich opportunities for learning, including both personal reflection and consideration of others' practice. They may learn from this as individuals, but this is no guarantee that what they learn can be scaled up to effect wider change, nor that their peers will experience the same kinds of learning they have had. Scaling up teacher development therefore remains a problem. Design-based approaches, such as pattern languages or those advocated in the design science literature, seek to capture and distribute pedagogic forms on an international basis; the effect of this scaling up would be to standardize practice around these forms. This appears to be in tension with the focus on contextual knowledge underlying existing approaches to teacher development, such as teacher inquiry. In this sense, the work described here adds to well established debates about the relative importance of pedagogic knowledge and pedagogic content knowledge, and draws attention back to the importance of pedagogical reasoning as a necessary step in contextualizing abstract advice (Wilson et al, 1987).

As sociomaterial theory suggests, and the cases presented here illustrate, teachers' practice is already mediated by multimodal texts that reify their day-to-day work. These occur in forms that they are already fluent in creating, reading and relating to their own practice, including stories and lesson plans. Clearly, more could be done to support teachers in learning from these school-based texts and practices; scaling up such learning represents an important opportunity for sharing successful approaches to education, and engendering a more inquiring stance across the profession. 
The desire to make sharing more efficient by creating and circulating abstract formalisms of practice remains problematic, however. The design-based approaches echo the division Dana \& Yendol-Hoppey (2008) draws between 'outsider' views of the teacher as technician (who can be made more efficient) and the 'insider' view of teacher as story teller associated with inquiry-based approaches to development. Theoretical perspectives such as Communities of Practice and sociomateriality, as well as the empirical evidence about design patterns and the cases presented here, all point towards the importance of discussion in making sense of these abstractions so that they can influence practice. Teachers can be helped to develop their capacity to create and interpret such representations, but this will require a consultant or expert to act as a boundary crossing agent, engaging with teachers as they learn to make sense of this new kind of pedagogic text.

An alternative to this orientation towards teaching as a 'design science' can be seen in the forms of public critique of teacher-authored texts advocated by Lieberman \& Pointer Mace (2010). Their call for "home grown professional learning [...] is not a call for the multimedia cavalry to gallop in and save teachers from professional isolation and stagnation" (p85). Instead, it focuses on expanding the productive discussions of schoolbased practice using the kinds of pedagogic text teachers are already familiar with, such as classroom materials, lesson plans or stories. Although these texts are easier for teachers to work with, even this carries challenges: teachers may not be ready to share such texts, nor even aware of what examples of such texts might be. There may also be scope to develop new languages with which to describe practice, as illustrated by the kinds of discussion that took place around the formalisms of the Visual Classroom's 'dashboard' representations of teaching practice (Skipp \& Tanner, 2015). The analysis of the cases presented here offers some examples, but more work can and should be done to explore the sociomateriality of teachers' practices. Such close investigation of existing successful practice may provide a productive and sharable alternative to current attempts to re-engineer teacher development.

\section{Acknowledgements}

The empirical work presented in this paper was undertaken as part of the NEXT-TELL project (Next Generation Teaching, Education and Learning for Life), reference 258114, funded by the European Union. 


\section{References}

Akkerman, S. \& Bakker, A. (2011) Boundary Crossing and Boundary Objects. Review of Educational Research, 81 (2), 132-169.

Barab, S., MaKinster, J., \& Sheckler, R. (2003) Designing system dualities: Characterizing a web-supported professional development community. The Information Society, 19 (3), 237-256.

Barton, D., \& Hamilton, M. (2005) Literacy, reification and the dynamics of social interaction. In Barton, D. \& Tusting (Eds), Beyond communities of practice: Language, power and social context, 14-35. Cambridge: Cambridge University Press.

Bull, S. \& Kay, J. (2013). Open Learner Models as Drivers for Metacognitive Processes. In R. Azevedo \& V. Aleven (eds), International Handbook of Metacognition and Learning Technologies, 349-365. New York: Springer.

Clark, W., Luckin, R. \& Jewitt, C. (2011) Methods and Specifications for TISL Components V1. NEXT-TELL project deliverable 5.1. Available online: http://next-

tell.eu/publications/project-deliverables/

Cochran-Smith, M. \& Lytle, S. (1999) The teacher research movement: A decade later. Educational Researcher, 28, 15-25.

Cochran-Smith, M., \& Lytle, S. L. (1999) Relationships of knowledge and practice: Teacher learning in communities. Review of Research in Education, 24, 249-305.

Cochran-Smith, M., \& Lytle, S. L. (2009). Inquiry as stance: Practi- tioner research for the next generation. New York, NY: Teachers College Press.

Dana, N. \& Yendol-Hoppey, D. (2008) The reflective educator's guide to classroom research: Learning to teach and teaching to learn through practitioner inquiry. Thousand Oaks: Corwin Press.

Dawson, K. (2007) The Role of Teacher Inquiry in Helping Prospective Teachers Untangle the Complexities of Technology Use in Classrooms. Journal of Computing in Teacher Education, 24, 5-12.

Fenwick, T., Edwards,R. \& Sawchuk, P. (2011) Emerging Approaches to Educational Research: Tracing the Sociomaterial. London: Routledge. 
Goodyear, P. (2005). Educational design and networked learning: patterns, pattern languages and design practice. Australasian Journal of Educational Technology, 21 (1), 82-101.

Goodyear, P. \& Steeples, C. (1998) Creating shareable representations of practice. Research in Learning Technology, 6 (3), 16-23.

Goodyear, P., \& Steeples, C. (1999) Asynchronous multimedia conferencing in continuing professional development: issues in the representation of practice through user-created videoclips. Distance Education, 20 (1), 31-48.

Grossman, P. L. (1990). The making of a teacher: Teacher knowledge and teacher education. Columbia: Teachers College Press.

Hamilton, M. (2011) Unruly Practices: What a Sociology of Translations Can Offer to Educational Policy Analysis. Educational Philosophy and Theory, 43: 55-75.

Hansen, C. \& Wasson, B. (2016) Teacher Inquiry into Student Learning: - The TISL Heart Model and Method for use in Teachers' Professional Development. Nordic Journal of Digital Literacy, 10 (1), 24-49.

Hines, M. \& Conner-Zachocki, J. (2015) Using practitioner inquiry within and against large-scale educational reform. Teacher Development, 19 (3), 344-364.

Hoekstra, A. \& Korthagen, F. (2011) Teacher Learning in a Context of Educational Change: Informal Learning Versus Systematically Supported Learning. Journal of Teacher Education. 63(1) 76-92.

Krumsvik, R. J. (2011). Digital competence in the Norwegian teacher education and schools. Högre utbildning, 1 (1), 39-51.

Lampert, M. (2010) Learning Teaching in, from, and for Practice: What Do We Mean? Journal of Teacher Education, 61 (1-2), 21-34.

Latour, B. (2005) Reassembling the Social. Oxford: Oxford University Press. Laurillard, D. (2008) The teacher as action researcher : Using technology to capture pedagogic form. Studies in Higher Education, 33 (2). pp. 139-154.

Laurillard, D. (2012) Teaching as a Design Science: Building Pedagogical Patterns for Learning and Technology. London: Routledge. 
Lieberman, A. \& Pointer Mace, D. (2010) Making Practice Public: Teacher Learning in the 21st Century. Journal of Teacher Education, 61 (1-2), 77-88.

Loo, S. (2013) Professional development of teachers: using multimodality and reflective peer review approaches to analyse digitally recorded teaching practices. Teacher Development, 17 (4), 499-517.

Luckin, R. 2010. Re-designing Learning Contexts: Technology-rich, Learner-centred Ecologies. London: Routledge.

Lytle, S. \& Cochran-Smith, M. (1994) Inquiry, knowledge, and practice. In Hollingsworth, S. \& Sockett, H. (eds.) Teacher research and educational reform. Chicago:IL: University of Chicago Press.

Marsh, B. \& Mitchell, N. (2014) The role of video in teacher professional development. Teacher Development, 18 (3), 403-417.

McAndrew, P., Goodyear, P., Dalziel, J. (2006). Patterns, designs and activities: unifying descriptions of learning structures. International Journal of Learning Technology, 2(2/3), 216-242.

Ramsten, A-C. \& Saljo, R. (2012) Communities, boundary practices and incentives for knowledge sharing?: A study of the deployment of a digital control system in a process industry as a learning activity. Learning, culture and social interaction, 1 (1), 33-44. Ritchie, G. (2006) Teacher research as a habit of mind. PhD, George Mason University. Rust, F. (2009) Teacher research and the problem of practice. The Teachers College Record, 111, 1882-1893.

Shulman, L. (1987). Knowledge and teaching: Foundations of the new reform. Harvard educational review, 57 (1), 1-23.

Skipp, A. \& Tanner, E. (2015) The Visible Classroom: Evaluation Report and Executive Summary. London: NatCen Social Research. https://educationendowmentfoundation.org.uk/uploads/pdf/Visible_Classroom_(Final) .pdf

Wang, J., Spalding, E., Odell, S., Klecka, C. \& Lin, E. (2010) Bold Ideas for Improving Teacher Education and Teaching: What We See, Hear, and Think. Journal of Teacher Education, 61 (1-2), 3-15. 
Wardrip, P., Gomez, L. \& Gomez, K. (2015) We modify each other's lessons: the role of literacy work circles in developing professional community. Teacher Development, 19 (4), 445-460.

Wenger, E. (1998) Communities of Practice: Learning, Meaning, and Identity. Cambridge: Cambridge University Press.

Wilson, S., Shulman, L., \& Richert, A. (1987). " 150 different ways" of knowing: Representations of knowledge in teaching. In Calderhead, J. (Ed.). Exploring teachers' thinking (pp. 104-124). London: Cassell.

Winters, N. \& Mor, Y. (2009) Dealing with abstraction: case study generalisation as a method for eliciting design patterns. Computers in Human Behavior, 25(5), 1079-1088. Winters, N. and Mor, Y. (2008) IDR: a participatory methodology for interdisciplinary design in technology enhanced learning. Computers and Education, 50 (2), 579-600. Zeichner, K. (2012) The Turn Once Again Toward Practice-Based Teacher Education, Journal of Teacher Education, 63 (5), 376-382.

Zuidema, L. (2012) Making Space for Informal Inquiry: Inquiry as Stance in an Online Induction Network. Journal of Teacher Education. 63(2) 132-146. 